\title{
The parallel development of ODD and CD symptoms from early childhood to adolescence
}

\author{
Sofia Diamantopoulou • Frank C. Verhulst • \\ Jan van der Ende
}

Received: 20 August 2010/ Accepted: 6 April 2011/Published online: 16 April 2011

(c) The Author(s) 2011. This article is published with open access at Springerlink.com

\begin{abstract}
This study examined the developmental relations between symptoms of oppositional defiant disorder (ODD) and conduct disorder (CD) from early childhood to adolescence. Specifically we tested, according to parentreported problems, whether symptoms of ODD precede the development of CD symptoms, whether ODD and CD symptoms are reciprocally associated across time, or whether ODD and CD symptoms develop parallel to each other across time. Participants were a community-based sample (at time 1: $N=485,48 \%$ boys) assessed biannually five times from age 4 to 6 until age 12-14. The findings suggested that, with control for stability effects, baseline SES, and symptoms of attention deficit hyperactivity disorder, ODD and CD symptoms develop parallel to each other. No gender differences were obtained. We conclude that without the initial presence of CD symptoms, ODD symptoms are not developmental precursors to $\mathrm{CD}$ symptoms.
\end{abstract}

Keywords Longitudinal study - Disruptive behavior problems · Child behavior checklist - Path-analyses . Gender differences

S. Diamantopoulou - F. C. Verhulst - J. van der Ende Department of Child and Adolescent Psychiatry, Erasmus MC, Sophia Children's Hospital, Rotterdam, The Netherlands

S. Diamantopoulou $(\bowtie)$

Department of Basic Psychology and Methodology,

Faculty of Psychology, University of Murcia,

Espinardo Campus, 30100 Murcia, Spain

e-mail: s.diamantopoulou@erasmusmc.nl

\section{Introduction}

Evidence suggests that oppositional defiant disorder (ODD) and conduct disorder (CD) are closely related in taxonomic and developmental terms [1]. Although ODD and CD are considered as two independent disorders, the behaviors that define ODD have long been hypothesized to be developmental precursors to serious conduct problems [2-4]. However, not all children with ODD will necessarily progress to CD [6-12] suggesting some discontinuity between the disorders. Determining whether ODD is a risk factor for, or develops secondarily to $\mathrm{CD}$ is of particular theoretical and clinical importance as it could suggest different etiological models and intervention efforts.

Table 1 provides an overview of prospective studies that examined the developmental relations between ODD and $\mathrm{CD}$. As shown in the table approximately half of the studies suggest that ODD and CD may represent the same underlying pathology as most children or youth with $\mathrm{CD}$ previously met diagnostic criteria for ODD or displayed elevated levels of ODD symptoms [2-4]. In support of the above, one study has even reported reciprocal temporal associations between the two constructs across time in terms of ODD symptoms preceding $\mathrm{CD}$ symptoms and vice versa $\mathrm{CD}$ symptoms preceding ODD symptoms [5]. Nevertheless, several studies in Table 1 report either no or weak prospective relations between childhood ODD and later developing CD [6-12]. Several methodological differences between the studies may explain the discrepant findings.

First, significant temporal associations between the two constructs are more likely in clinical- than in communitybased samples [6, 8]. However, because clinical samples are typically subject to higher rates of comorbidity, studies of clinical samples may have exaggerated the degree of the temporal relations between ODD and CD [13]. Second, in 
Table 1 Overview of prospective studies examining the temporal relations between ODD and CD

\begin{tabular}{|c|c|c|c|c|c|c|}
\hline Reference & Sample & $\begin{array}{l}\text { Baseline } \\
\text { age } \\
\text { (years) }\end{array}$ & $\begin{array}{l}\text { Follow-up } \\
\text { age } \\
\text { (years) }\end{array}$ & $\begin{array}{l}\text { Diagnostic } \\
\text { instrument }\end{array}$ & Data analyses & Main findings \\
\hline $\begin{array}{l}\text { August } \\
\text { et al. [6] }\end{array}$ & $\begin{array}{l}\text { Community-based; } \\
308 \text { children } \\
\text { with disruptive } \\
\text { behavior } \\
\text { problems }\end{array}$ & $6-10$ & $11-15$ & $\begin{array}{l}\text { Parent and teacher } \\
\text { ratings at baseline; } \\
\text { diagnostic } \\
\text { interview at } \\
\text { follow-up }\end{array}$ & $\begin{array}{l}\text { Presence or absence of } \\
\text { ADHD, ODD, or CD } \\
\text { diagnosis at follow-up } \\
\left(\chi^{2}\right)\end{array}$ & $\begin{array}{l}\text { Only } 1 \text { of } 43 \text { children with } \\
\text { ADHD + ODD at T1 } \\
\text { developed CD at follow-up }\end{array}$ \\
\hline $\begin{array}{l}\text { Biederman } \\
\text { et al. [7] }\end{array}$ & $\begin{array}{l}140 \text { children with } \\
\text { DSM-III-R } \\
\text { ADHD diagnosis } \\
\text { and } 120 \text { controls }\end{array}$ & $6-17$ & $\begin{array}{l}16-27 \text { at } \\
\text { follow-up }\end{array}$ & $\begin{array}{l}\text { Diagnostic } \\
\text { interviews }\end{array}$ & $\begin{array}{l}\text { LRA predicting presence or } \\
\text { absence of CD diagnosis } \\
\text { at follow-up }\end{array}$ & $\begin{array}{l}\text { Most children with } \\
\text { ADHD + ODD did not } \\
\text { progress to CD at follow-up }\end{array}$ \\
\hline $\begin{array}{l}\text { Burke et al. } \\
\text { [5] }\end{array}$ & $\begin{array}{l}\text { Clinic-referred; } \\
177 \text { boys with } \\
\text { disruptive } \\
\text { behavior } \\
\text { disorders }\end{array}$ & $7-12$ & $\begin{array}{l}\text { Annual } \\
\text { assessments } \\
\text { until age } 18\end{array}$ & $\begin{array}{l}\text { Diagnostic } \\
\text { interviews }\end{array}$ & $\begin{array}{l}\text { GEE predicting symptom } \\
\text { counts in wave } \mathrm{T}+1 \\
\text { from wave } \mathrm{T}\end{array}$ & $\begin{array}{l}\text { At all time points CD } \\
\text { symptoms were predicted by } \\
\text { previous ODD symptoms }\end{array}$ \\
\hline $\begin{array}{l}\text { Costello } \\
\text { et al. [8] }\end{array}$ & $\begin{array}{l}\text { Community-based; } \\
1420 \text { children }\end{array}$ & $9-13$ & $\begin{array}{l}\text { Annual } \\
\text { assessments } \\
\text { until age } 16\end{array}$ & $\begin{array}{l}\text { Diagnostic } \\
\text { interviews (DSM- } \\
\text { IV) }\end{array}$ & $\begin{array}{l}\text { LRA predicting ODD or } \\
\text { CD diagnosis at each time } \\
\text { point from previous time } \\
\text { points }\end{array}$ & $\begin{array}{l}\text { At no time point did ODD } \\
\text { predict subsequent } \mathrm{CD} \text { and at } \\
\text { no time point did CD predict } \\
\text { subsequent ODD }\end{array}$ \\
\hline $\begin{array}{l}\text { Harvey } \\
\text { et al. [3] }\end{array}$ & $\begin{array}{l}168 \text { children with } \\
\text { behavior } \\
\text { problems at } \\
\text { baseline }\end{array}$ & 3 & 6 & $\begin{array}{l}\text { Diagnostic } \\
\text { interviews }\end{array}$ & $\begin{array}{l}\text { LRA predicting ODD/CD } \\
\text { diagnosis at follow-up } \\
\text { from baseline symptoms }\end{array}$ & $\begin{array}{l}\text { Moderate positive associations } \\
\text { between ODD symptoms at } \\
\text { baseline and combined ODD/ } \\
\text { CD diagnosis at follow-up }\end{array}$ \\
\hline $\begin{array}{l}\text { Lahey et al. } \\
\text { [5] }\end{array}$ & $\begin{array}{l}\text { As in Burke et al. } \\
\text { (2005) above }\end{array}$ & $7-12$ & $\begin{array}{l}\text { Annual } \\
\text { assessments } \\
\text { over } 7 \text { years }\end{array}$ & $\begin{array}{l}\text { Diagnostic } \\
\text { interviews (DSM- } \\
\text { III, DSM-III- R, \& } \\
\text { DSM-IV) }\end{array}$ & $\begin{array}{l}\text { Modeled mean numbers of } \\
\text { ODD and CD symptoms } \\
\text { longitudinally in GEE }\end{array}$ & $\begin{array}{l}\text { Reciprocal temporal relations } \\
\text { between ODD and CD } \\
\text { symptoms were obtained for } \\
\text { all assessments }\end{array}$ \\
\hline $\begin{array}{l}\text { Lahey et al. } \\
\text { [9] }\end{array}$ & $\begin{array}{l}\text { Community based; } \\
6,994 \text { children }\end{array}$ & $4-7$ & $8-13$ & $\begin{array}{l}\text { Parent ratings } \\
\quad(\mathrm{CBCL} \text { items })\end{array}$ & $\begin{array}{l}\text { Log linear regressions; } \\
\text { ODD and ADHD } \\
\text { symptoms predicting } \\
\text { conduct problems }\end{array}$ & $\begin{array}{l}\text { With control for baseline } \\
\text { conduct problems, ADHD } \\
\text { and ODD } \\
\text { symptoms predicted follow-up } \\
\text { conduct problems only to a } \\
\text { small extent }\end{array}$ \\
\hline $\begin{array}{l}\text { Mannuzza } \\
\text { et al. [10] }\end{array}$ & $\begin{array}{l}\text { Clinical sample; } \\
207 \text { boys with } \\
\text { DSM-II } \\
\text { hyperkinetic } \\
\text { reaction }\end{array}$ & $6-12$ & 18 & $\begin{array}{l}\text { Parent and teacher } \\
\text { ratings at baseline; } \\
\text { diagnostic } \\
\text { interviews at } \\
\text { follow-up }\end{array}$ & $\begin{array}{l}\text { LRA predicting adolescent } \\
\text { CD diagnosis }\end{array}$ & $\begin{array}{l}\text { Childhood ODD behaviors did } \\
\text { not predict adolescent CD } \\
\text { diagnosis }\end{array}$ \\
\hline $\begin{array}{l}\text { Rowe et al. } \\
\text { [11] }\end{array}$ & $\begin{array}{l}\text { Community } \\
\text { sample; } 1,420 \\
\text { children }\end{array}$ & $9-13$ & $\begin{array}{l}\text { Four annual } \\
\text { assessments }\end{array}$ & $\begin{array}{l}\text { Diagnostic } \\
\text { interviews }\end{array}$ & $\begin{array}{l}\text { LRA predicting ODD or } \\
\text { CD at waves } 2-4 \text { from } \\
\text { wave } 1\end{array}$ & $\begin{array}{l}\text { Boys: ODD at wave } 1 \\
\text { predicted both ODD and CD } \\
\text { at waves } 2-4 \text {. Girls: None of } \\
\text { the girls with ODD at wave } \\
\text { 1developed CD at later waves }\end{array}$ \\
\hline $\begin{array}{l}\text { Speltz et al. } \\
\text { [12] }\end{array}$ & $\begin{array}{l}\text { Clinical sample of } \\
79 \text { boys with } \\
\text { DSM-III-R ODD }\end{array}$ & $4-5.5$ & $6-7.5$ & $\begin{array}{l}\text { Diagnostic } \\
\text { interviews (DSM- } \\
\text { III-R diagnoses) }\end{array}$ & $\begin{array}{l}\text { Presence or absence of } \\
\text { ODD and CD diagnosis at } \\
\text { follow-up }\left(\chi^{2}\right)\end{array}$ & $\begin{array}{l}\text { At follow-up } 30 \% \text { of the boys } \\
\text { received an ODD diagnosis } \\
\text { and only two cases met } \\
\text { criteria for CD }\end{array}$ \\
\hline $\begin{array}{l}\text { Whittinger } \\
\text { et al. [4] }\end{array}$ & $\begin{array}{l}\text { Clinical sample of } \\
151 \text { children } \\
\text { with DSM-IV } \\
\text { ADHD }\end{array}$ & $6-13$ & $11-18$ & $\begin{array}{l}\text { Diagnostic } \\
\text { interviews (DSM- } \\
\text { IV diagnoses) }\end{array}$ & $\begin{array}{l}\text { LRA predicting ADHD, } \\
\text { ODD, and CD diagnoses } \\
\text { at follow-up }\end{array}$ & $\begin{array}{l}39 \% \text { of children with an ODD } \\
\text { diagnosis met criteria for a } \\
\text { CD diagnosis in adolescence }\end{array}$ \\
\hline
\end{tabular}

$L R A$ Logistic regression analysis, $G E E$ generalized estimating equations, $C B C L$ child behavior checklist 
the DSM [14] CD and ODD are not allowed to be comorbid diagnoses. As a result, the use of clinical cut-offs in assigning ODD and CD diagnoses in studies may have boosted the prediction of CD from previous levels of ODD when subclinical levels of CD have not been considered, whereas the appearance of more 'severe' manifestations of CD may have overshadowed the stability of ODD. Only two studies in Table 1 utilized a dimensional approach assessing the two constructs as a continuum to avoid over- or underestimating their temporal relations and reached strikingly different conclusions: ODD is [2] and ODD is not [10] a precursor of CD. Perhaps, the discrepant findings of the two above studies are due to the use of different ODD measures (i.e., DSM-III-R ODD diagnosis based on clinic interviews in the study by Burke et al.; retrospective DSM-IV ODD diagnosis based on parent and teacher questionnaires in the study by Mannuzza et al.). Third, as two literature reviews suggest that ODD is more likely to be a precursor of CD in early (i.e., up to the age of 7 years) than in late childhood [1, 15], age effects may explain the studies' discrepant findings. For instance, two studies in Table 1 that measured ODD in early childhood [3,9] reported significant prospective associations between ODD and CD, whereas two studies that measured ODD after the age of six reported weak or no prospective associations between ODD and CD $[4,6]$. Finally, discrepancies between the findings in the literature may also be due to the use of different conceptualizations of ODD and CD including diagnoses according to older versions of the DSM [10, 12], diagnoses based on parental questionnaires [6,9] versus diagnostic interviews $[2,5]$. Clearly, more research on the temporal relations between ODD and CD assessing the two constructs dimensionally from early childhood to adolescence is needed.

Certain limitations in the literature need also to be overcome if we are to understand the relations between ODD and CD across time. First, because of the higher prevalence of ODD and CD in boys as compared to girls $[16,17]$, little is known about the development of the two constructs in girls. Interestingly, the one study that examined gender differences in the prospective associations between ODD and CD showed that ODD appears to be a developmental precursor to CD only among boys [11]. Second, because symptoms of attention deficit hyperactivity disorder (ADHD) often co-occur with both ODD and $\mathrm{CD}$ and may even partly account for the developmental progression of ODD into CD [18] studies need to control for ADHD symptoms when examining the developmental relations between ODD and CD.

This study aimed to overcome the above limitations in the literature and disentangle the developmental relations between ODD and CD symptoms from early childhood to adolescence assessing the two constructs dimensionally in a community-based sample.

\section{Method}

Participants and procedure

This study is based on data derived from a seven-wave, multi-cohort, longitudinal study of behavioral and emotional problems in children that started in 1983 [19]. The original sample of 2,600 children from 13 birth cohorts aged 4-16 was drawn from municipal registers that list all residents in the Dutch province of Zuid-Holland. A random sample of 100 children of each gender and age of Dutch nationality was drawn. Of the 2,447 parents reached, 2,076 (i.e., 84.8\%) provided usable data. The sample in 1983 consisted of 1,106 boys and 1,060 girls. This sample was assessed biannually five times (until 1991; Time 5), once 6 years later (1997; Time 6) and then again in 2007 (Time 7). The present study is based on data from Time 1 to Time 5. As we aimed to examine the temporal relations between symptoms of ODD and CD from early childhood to adolescence, we selected an age-appropriate subsample of children who were aged 4-6 years at baseline. The number and age of the participants at each time point was: 485 (231 boys) age 4-6 years at Time 1, 373 (184 boys) age 6-8 years at Time 2, 326 (167 boys) age 8-10 years at Time 3, 311 (164 boys) age 10-12 years at Time 4 , and 305 (160 boys) age 12-14 years at Time 5. We obtained written informed consent by all participants after the procedures were fully explained and the local ethical committee approved the data collection. The ethnic composition of the sample was 97\% Dutch (remaining 3\% came from Surinam, the Dutch Antilles, and Morocco). Participants who remained in the study at Time 5 did not differ significantly in any study variables from those who had dropped out $(-0.16 \leq \mathrm{ts} \leq 1.82$, ns $)$.

\section{Measures}

\section{$O D D, C D$, and ADHD symptoms}

We obtained parent ratings of children's symptoms of ODD, CD, and ADHD over the past 6 months on the Child Behavior Checklist (CBCL; [20, 21]). Ratings were made on a three-point scale $(0=$ not true, $1=$ somewhat or sometimes true, 2 = very true or often true) and we used the summed score of items for all the scales. The CBCL has been translated and validated for use in The Netherlands [22]. CBCL items reflecting a similar content to DSM-IV criteria for ODD, CD, and ADHD were used in the analyses (i.e., the DSM-oriented scales; [23]). Due to the use of the earlier versions of the CBCL (i.e., the 1983 version at times 1-4 and the 1991 version at time 5) that did not include the DSM-oriented scales that were developed in the later version (i.e., 2001) of the instrument, not 
all items of the scales were included (i.e., at all time points the items "fails to finish" and "inattentive" for the ADHD scale, and the item "breaks rules" for the CD scale were not included). The items and the internal consistency of the scales measured as Cronbach's alpha are presented in Table 2.

Although the DSM-oriented scales of the CBCL have not been used in the literature as much as the empirically derived syndrome scales of the instrument, there is some evidence for their psychometric properties. For instance, in a Dutch clinical sample $(N=44)$, the correlations (phi) between the DSM-oriented scales of ADHD, ODD, and CD and the equivalent diagnoses obtained by the Diagnostic Interview Schedule for Children (DISC-IV) ranged from 0.43 , to $0.67, p<0.01$ [24]. In a large multi-ethnic, clinical sample $(N=673)$ the internal consistency of the scales was high (Cronbach's alpha $\geq 0.85$ ), children and youths diagnosed with ADHD, ODD, or CD scored higher on the respective scales as compared to those without a diagnosis, and finally the correlation between parent ratings on the three DSM-oriented scales correlated significantly high (rs $\geq 0.56$ ) with parental dimensional ratings of hyperactivity/ impulsivity and inattention symptoms and oppositional and delinquent behavior [25].

To confirm that the ODD and CD items form two separate factors at times $1-5$, we conducted confirmatory factor analyses (CFAs) using Mpuls version 5.0 [26]. To account for the ordinal item responses, we applied weighted least squares estimation (WLSE) analyses. To avoid statistical

Table 2 CBCL/4-18 items included in the ADHD, ODD, and CD symptom scales

\begin{tabular}{|c|c|c|}
\hline $\operatorname{ADHD}(0.70 \leq \alpha \leq 0.75)$ & & $\begin{array}{l}\text { ODD } \\
\qquad(0.70 \leq \alpha \leq 0.74)\end{array}$ \\
\hline Cannot concentrate & & Argues a lot \\
\hline Cannot sit still & & $\begin{array}{l}\text { Disobedient at } \\
\text { school }\end{array}$ \\
\hline $\begin{array}{l}\text { Impulsive or acts without } \\
\text { thinking }\end{array}$ & & Disobedient at home \\
\hline Talks too much & & Stubborn \\
\hline Loud & & Hot temper \\
\hline \multicolumn{3}{|l|}{$\mathrm{CD}(0.55 \leq \alpha \leq 0.80)$} \\
\hline Cruel to animals & Runs away & \\
\hline Mean to others & Sets fires & \\
\hline Destroys other's things & Steals at home & \\
\hline Lacks guilt & $\begin{array}{l}\text { Steals outside } \\
\text { home }\end{array}$ & \\
\hline Fighting & Swears & \\
\hline Lying, cheating & $\begin{array}{l}\text { Threatens } \\
\text { people }\end{array}$ & \\
\hline Attacks people & Truancy & \\
\hline Bad companions & Vandalism & \\
\hline
\end{tabular}

risks associated with low frequency cells, we applied WLS analyses to tetrachoric correlations between item scores dichotomized as 0 versus 1 or 2 . We compared a one-factor model where all items were hypothesized to measure a single underlying general factor with a correlated 2-factor model representing the two DSM-oriented scales of the CBCL for ODD and CD where each item was assigned to the syndrome it was supposed to measure. Model fit was assessed with the comparative fit index (CFI; [27]) that is based on the average size of the correlations in the data. Models with a CFI close to 1 are considered to be fitting the observed data well. Model selection was based on the differences in the two models' root mean square error of approximation (RMSEA; [27]) which is a measure of the empirical validity of the tested models (i.e., how well the models fit the observed data). According to guidelines [28], better fitting models are accepted when the change in the RMSEA ( $\triangle$ RMSEA) is equal or greater than 0.01 . When the fit of a more complex model does not differ from the fit of a more parsimonious model, then the more parsimonious model is accepted. Finally, we conducted chi-square difference tests to compare the fit of the one- and two-factor models. The results showed that the model fit of the one- and the two-factor model was good at all time points (one-factor model: $0.69 \leq \mathrm{CFI} \leq 0.92$; two-factor model: $0.75 \leq$ $\mathrm{CFI} \leq 0.95$ ) except for Time 5 for the one-factor model $(\mathrm{CFI}=0.69)$. However, model comparison showed that, at each time point, the two-factor model fitted the data better than a one-factor model ( $\triangle$ RMSEA $\geq 0.01$ ) confirming the measurement quality of the ODD and CD scales. Results of the chi-square difference tests showed that at all time points the two-factor model fitted the data better (i.e., the twofactor model had a lower $\chi^{2}$ ) than a one-factor model: $\chi^{2}$ [1] $\geq 10.28, p<0.01$. The correlation between the two latent factors in the two-factor CFA ranged from $r=0.36$ $p<0.01$ at Time 5 to $r=0.81, p<0.01$ at Time 2 .

SES

Data on SES were obtained at Time 1 according to a sixstep scale of parental education with ascending numbers indicating higher SES [29].

Statistical analyses

We computed Pearson's correlation coefficients to assess the relations between all study variables and examined gender differences in all variables with two-tailed $t$-tests. We examined the developmental relations between symptoms of ODD and CD using path modeling with Mplus [26]. Because the data departed from multivariate normality (see Table 2) we used full information maximum likelihood parameter estimates with standard errors that are 


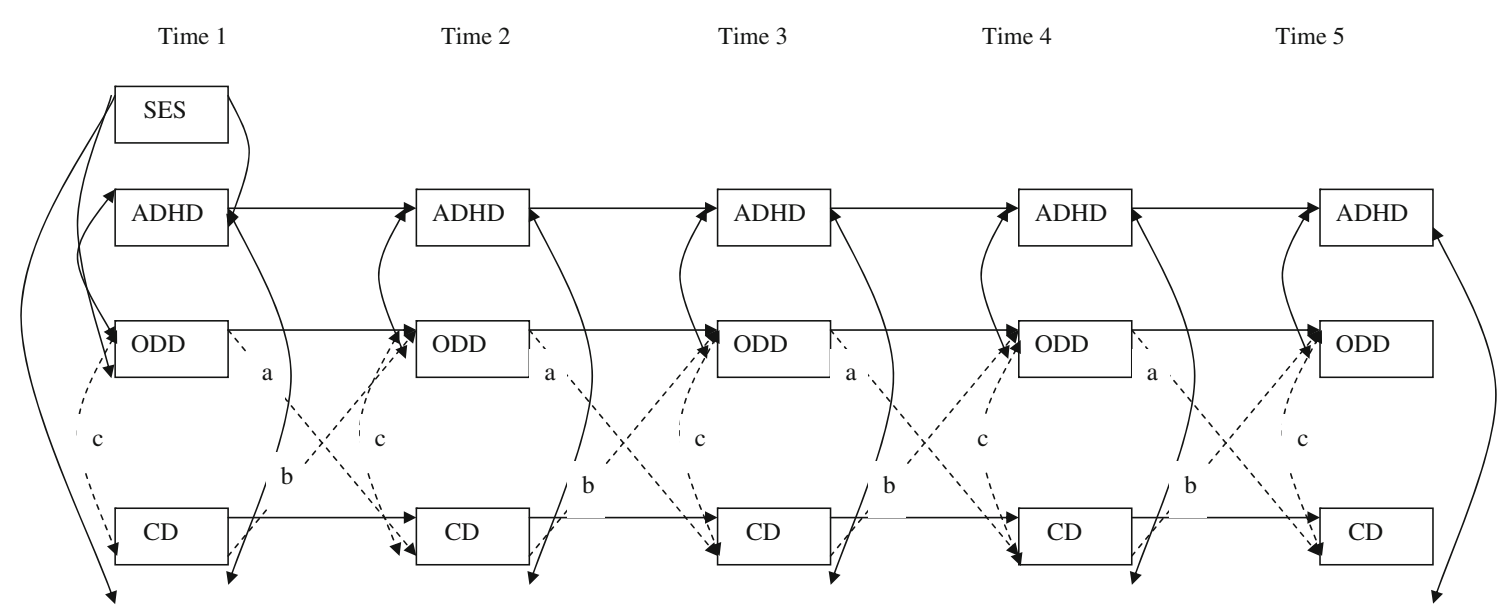

Fig. 1 Illustration of the three tested models. All three models include the same directional and correlation (solid) paths but, of the dotted paths, the cross-lagged model includes paths $a, b$, and $c$, the

robust to non-normality (i.e., MLR). Maximum likelihood estimation procedure is particularly appropriate for longitudinal studies that often contain missing data [30]. Chisquare difference analyses guided decisions concerning selection of the best fitting model (i.e., the Satorra-Bentler scaled chi-square difference test which is appropriate for models estimated with MLR; [31]). The goodness-of-fit of the models was evaluated by using two indicators: the root mean square error of approximation (RMSEA) where values below 0.06 indicate a good fit [27] and the CFI where values larger than 0.90 or close to 0.95 indicate a good fit [32].

Figure 1 depicts the three competing models that we tested. The first model assumed reciprocal temporal associations between ODD and CD symptoms across time and therefore included, apart from stability paths and crosssectional correlations, cross-lagged paths between the two constructs (i.e., the cross-lagged model). The second model assumed that only ODD symptoms predict subsequent CD symptoms and therefore included apart from stability paths and cross-sectional correlations, directional paths only from previous ODD symptoms to subsequent CD symptoms (i.e., the unidirectional model). The third model assumed parallel but associated development of ODD and CD symptoms across time and included, apart from stability paths, only cross-sectional correlation paths between the two constructs (i.e., the correlational model). In all models, we controlled for SES at Time 1 and for ADHD symptoms at all time points (depicted as correlational paths in Fig. 1). Included in the model but not depicted in Fig. 1 are covariances between the residuals of ADHD, ODD, and $\mathrm{CD}$ symptoms from Time $t$ to Time $t+1$. The models were tested on the whole sample and separately for boys and girls. unidirectional model includes only paths $b$ and $c$, and the correlational model includes only paths $c$

\section{Results}

The correlation matrix, the means, and the standard deviations for the measured variables are shown in Table 3. As seen in the table, both ODD and CD symptoms were always correlated with their previous levels across time. The concurrent correlations between ODD and CD symptoms, between ODD and ADHD, and between CD and ADHD symptoms were always positive and significant. At Time 1, SES was negatively correlated with ODD, CD, and ADHD symptoms. Examination of gender differences showed that boys as compared to girls had higher levels of ODD symptoms at the first two time points and they had higher levels of ADHD and CD symptoms at all time points $(2.15 \leq$ ts $\leq 4.17 ; p<0.01)$.

All three models provided an equally good fit to the data: $\mathrm{CFI}=0.97$, RMSEA $=0.04$ for all three models However, in the cross-lagged model none of the crosslagged paths (i.e., paths a and b in Fig. 1) were significant whereas in the unidirectional model none of the paths to subsequent CD symptoms from previous ODD symptoms (i.e., paths a) were significant. The chi-square difference tests indicated that: (a) the unidirectional model did not yield a deteriorated model fit compared to the cross-lagged model $\left(\Delta \chi^{2}[4]=2.66, \mathrm{~ns}\right)$ and, (b) the correlational model did not yield a deteriorated model fit compared both to the cross-lagged model $\left(\Delta \chi^{2}[8]=5.54, \mathrm{~ns}\right)$ and to the unidirectional model $\left(\Delta \chi^{2}[4]=2.89, \mathrm{~ns}\right)$. When we examined the three models separately for boys' and girls' data results were replicated (Boys: $\mathrm{CFI}=0.96$, RMSEA $=0.05$ for the three models; Girls: CFI $=0.97$, RMSEA $=0.04$ for the three models; none of the cross-lagged or the unidirectional paths between ODD and CD symptoms were significant for boys' or for girls' data). Chi-square 
Table 3 Correlation matrix and means (M) and standard deviations (SD) for observed variables

\begin{tabular}{|c|c|c|c|c|c|c|c|c|c|c|c|c|c|c|c|c|}
\hline & 1 & 2 & 3 & 4 & 5 & 6 & 7 & 8 & 9 & 10 & 11 & 12 & 13 & 14 & 15 & 16 \\
\hline $1 \mathrm{ODD} \mathrm{T} 1$ & 1.00 & & & & & & & & & & & & & & & \\
\hline 2 ODD T2 & 0.54 & 1.00 & & & & & & & & & & & & & & \\
\hline 3 ODD T3 & 0.46 & 0.57 & 1.00 & & & & & & & & & & & & & \\
\hline 4 ODD T4 & 0.44 & 0.55 & 0.59 & 1.00 & & & & & & & & & & & & \\
\hline 5 ODD T5 & 0.39 & 0.44 & 0.51 & 0.64 & 1.00 & & & & & & & & & & & \\
\hline $6 \mathrm{CD} \mathrm{T} 1$ & 0.48 & 0.38 & 0.34 & 0.35 & 0.27 & 1.00 & & & & & & & & & & \\
\hline $7 \mathrm{CD}$ T2 & 0.36 & 0.59 & 0.35 & 0.39 & 0.35 & 0.45 & 1.00 & & & & & & & & & \\
\hline $8 \mathrm{CD}$ T3 & 0.29 & 0.42 & 0.50 & 0.48 & 0.32 & 0.39 & 0.50 & 1.00 & & & & & & & & \\
\hline $9 \mathrm{CD} \mathrm{T} 4$ & 0.21 & 0.31 & 0.33 & 0.57 & 0.49 & 0.40 & 0.47 & 0.58 & 1.00 & & & & & & & \\
\hline $10 \mathrm{CD}$ T5 & 0.20 & 0.30 & 0.31 & 0.48 & 0.56 & 0.29 & 0.47 & 0.47 & 0.71 & 1.00 & & & & & & \\
\hline 11 ADHD T1 & 0.53 & 0.37 & 0.37 & 0.34 & 0.18 & 0.40 & 0.29 & 0.26 & 0.14 & $0.09^{\mathrm{a}}$ & 1.00 & & & & & \\
\hline 12 ADHD T2 & 0.36 & 0.54 & 0.36 & 0.39 & 0.22 & 0.38 & 0.53 & 0.40 & 0.30 & 0.28 & 0.60 & 1.00 & & & & \\
\hline 13 ADHD T3 & 0.28 & 0.31 & 0.47 & 0.36 & 0.20 & 0.22 & 0.30 & 0.44 & 0.22 & 0.15 & 0.57 & 0.68 & 1.00 & & & \\
\hline 14 ADHD T4 & 0.30 & 0.25 & 0.35 & 0.48 & 0.29 & 0.33 & 0.35 & 0.43 & 0.41 & 0.36 & 0.50 & 0.68 & 0.75 & 1.00 & & \\
\hline 15 ADHD T5 & 0.28 & 0.18 & 0.32 & 0.42 & 0.38 & 0.26 & 29 & 0.35 & 0.36 & 0.41 & 0.46 & 0.60 & 0.69 & 0.79 & 1.00 & \\
\hline 16 SES T1 & -0.13 & -0.13 & -0.14 & -0.20 & -0.15 & -0.13 & -0.15 & -0.11 & -0.12 & -0.19 & -0.18 & -0.16 & -0.24 & -0.20 & -0.22 & 1.00 \\
\hline M & 2.26 & 1.98 & 1.84 & 2.10 & 2.07 & 1.06 & 0.98 & 0.76 & 0.89 & 0.83 & 2.95 & 2.58 & 2.55 & 2.43 & 2.27 & 3.47 \\
\hline SD & 1.96 & 1.84 & 1.89 & 1.89 & 1.93 & 1.67 & 1.62 & 1.23 & 1.62 & 1.69 & 2.37 & 2.32 & 2.33 & 2.34 & 2.34 & 1.57 \\
\hline
\end{tabular}

T1 Time 1, T2 Time 2, T3 Time 3, T4 Time 4, T5 Time 5

All correlations significant at $p<0.05$ level or lower except for correlations marked with ${ }^{\text {a }}$ that were not significant

difference tests indicated that the correlational model did not yield a deteriorated model fit compared both to the cross-lagged and the unidirectional model for both boys' and girls' data $\left(3.73 \leq \Delta \chi_{\mathrm{s}}^{2} \leq 6.85, d f=4-8\right.$, ns).

Because the most parsimonious, correlation model fitted the data equally well as the cross-lagged- and the univariate model, we selected it as the final model. The standardized estimates for the correlational model are depicted in Fig. 2. Considering time intervals of 2 years for the five assessments, temporal stabilities for ODD, CD, and ADHD symptoms were high. The concurrent associations between ODD and CD symptoms were high across time and so were the associations between ADHD symptoms and the two constructs.

To further examine the influence of ADHD symptoms on the temporal relations between ODD and CD symptoms, we examined the cross-lagged, unidirectional, and correlational models without control for ADHD symptoms. These three models also fitted the data well: $\mathrm{CFI}=0.99$ for all three models and RMSEA $=0.02$ for the crosslagged and the unidirectional models and RMSEA $=0.03$ for the correlational model. Comparison of the models indicated that although the model fit of the cross-lagged versus the unidirectional model did not differ significantly $\left(\Delta \chi^{2}[4]=6.09\right.$, ns), the cross-lagged and the unidirectional models fitted the data better than the correlational model $\left(\Delta \chi^{2}[8]=19.21, p<0.05\right.$ and $\Delta \chi^{2}[4]=14.22$, $p<0.05$, respectively). However, none of the cross-lagged or unidirectional paths reached statistical significance indicating that even without control for ADHD symptoms ODD symptoms did not significantly predict subsequent $\mathrm{CD}$ symptoms and ODD and CD symptoms were not reciprocally associated across time. Results of analyses conducted separately for boys and girls replicated the above findings for boys but for girls the three models fitted the data equally well.

\section{Discussion}

This study examined whether ODD symptoms should be viewed as precursors of later developing $\mathrm{CD}$, whether ODD and CD are likely to show reciprocal temporal associations across time, or finally, whether ODD and CD develop parallel to each other. In line with the findings of previous studies of community-based samples, no temporal associations between $\mathrm{ODD}$ and $\mathrm{CD}$ symptoms were observed $[6,8]$. Instead, the strongest predictor of subsequent CD symptoms was initial CD symptoms. What this study adds to the literature is that we confirm these findings for a lengthy follow-up period spanning from early childhood to adolescence, for both genders, using multiple assessments.

Keeping in mind that causal interpretations of results of longitudinal path analyses should be avoided and results should be interpreted with caution, the present findings do 


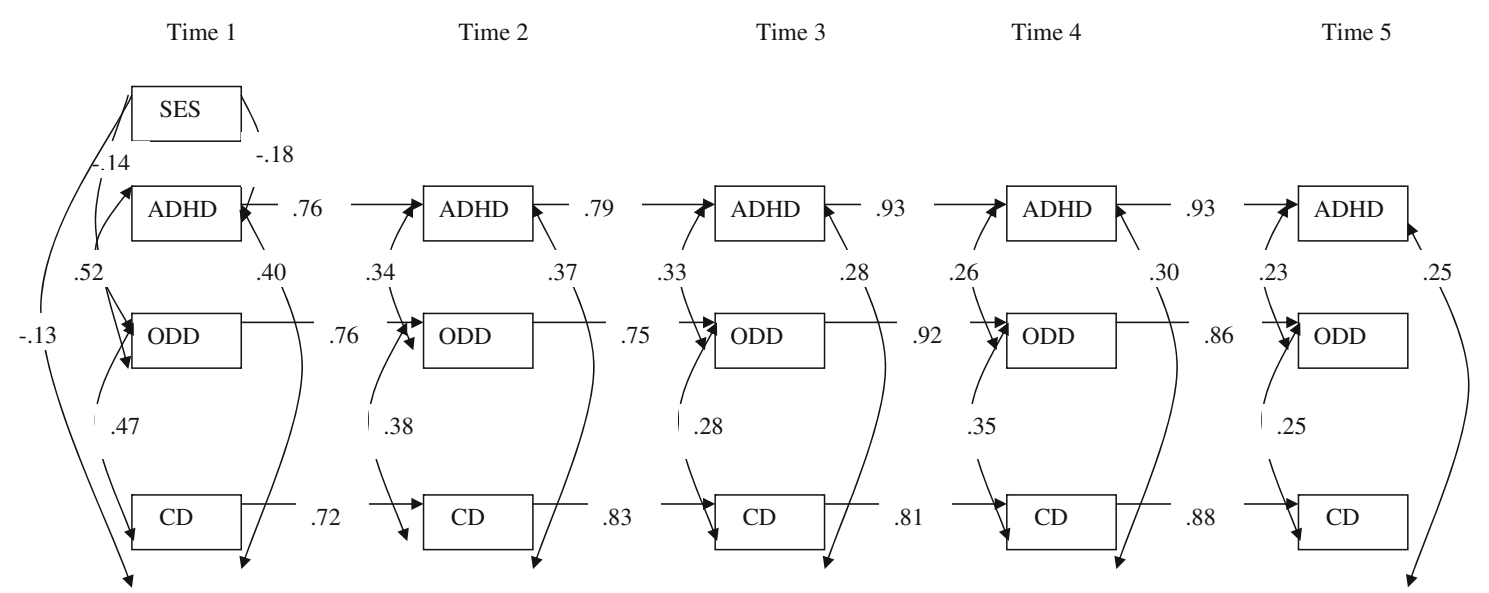

Fig. 2 Final correlational model. Note: All paths significant at $p<0.01$ level

not suggest that ODD symptoms are a milder, earlier manifestation of CD. Neither do the results suggest that ODD symptoms may develop secondarily to CD symptoms, as none of the paths between ODD and CD symptom levels in the unidirectional and the cross-lagged models were significant. The results are in line with the study by Lahey et al. [9] that also used CBCL items to predict conduct problems from ADHD and ODD symptoms in a community-based sample. It should, however, be noted that the high temporal stability of both ODD and CD symptoms renders reciprocal associations between the two constructs less probable insofar as the greater the stability of a construct, the less the chance of finding other variables that potentially explain its variance [33].

In contrast to the findings by Rowe et al. [11], which are also based on a community-based sample, the temporal relations between ODD and CD symptoms did not differ by gender in this study. One possible reason for this is that whereas Rowe et al. [11] based their results on analyses utilizing clinical cut-offs, we examined the temporal relations between ODD and CD dimensionally in a sample that overall did not display very high symptom levels. Consequently, the findings of this study indicate that as long as negativistic and defiant behaviors in childhood are mild to moderate and do not reach clinical levels, boys and girls are equally likely to either outgrow these problems or not develop more serious conduct problems. Future studies need to examine whether the above findings hold even after control for other comorbid psychopathology such as depression and anxiety that may have different relations with ODD and CD symptoms in boys and girls.

Some previous studies suggest that children with ODD and ADHD are more likely to develop CD than children with ODD only [18]. Consequently, removal of ADHD symptoms from the measurement model should render the unidirectional model as better fitting than the correlational model. Nevertheless, results did not suggest such an effect although the concurrent associations between ADHD symptoms and both ODD and CD symptoms were significantly positive across all time points. Hence, it appears that in community-based samples, the impact of ADHD symptoms on the temporal relations between ODD and CD is minimal.

This study is not without limitations. First, like most previous longitudinal studies that examined the prospective relations between oppositional-, inattentive/hyperactive behaviors and later conduct problems the present analyses were not based on measures that were a perfect match to the DSM-IV symptom-criteria. A recent, large $(N=476)$, multi-ethnic, clinical study of children and adolescents confirmed the construct and discriminant validity of the DSM-oriented scales showing that the scales corresponded well (area under the curve values $\geq 0.71$ ) with related clinical diagnoses [34]. However, it should be noted that in this latter study, the DSM-oriented scales of the CBCL for ODD, CD, and ADHD did not show greater correspondence with corresponding clinical diagnoses than the CBCL empirically derived syndrome scales of aggressive behavior, rule-breaking behavior, and attention problems. Moreover, the present findings are quite consistent with the smaller set of studies that did use DSM-based measures in terms of the concurrent associations found between ODD, $\mathrm{CD}$, and ADHD (e.g. 5, 7) suggesting that the findings of this study are relevant to DSM conceptualizations of these disorders. Nevertheless, because different results may have been obtained had we used DSM-based measures, future longitudinal studies using such measures would be very useful. Second, because of the use of parent ratings, results may not generalize to studies using teacher or self-ratings of ODD and CD symptoms. Finally, the reliability of the $\mathrm{CD}$ scale at the first two time points was relatively low. Inspection of the results of the CFAs, we conducted showed that this was primarily caused by low loadings of two CD scale items namely, "Truancy" and "Threatens 
people". The results are not unexpected given that at the first two time points of the study participants were very young and therefore, highly unlikely to attempt to be absent from school or have fully developed the language and cognitive skills in order to seriously threaten others.

One of the strengths of this study is that the multiple assessments allowed for the examination of competing models in terms of their ability to explain the dynamic, temporal linkage between ODD and CD symptoms. In conclusion, the findings suggest that the best predictor of subsequent CD symptoms is initial CD symptoms. However, ODD symptoms appear to carry unique information not captured by CD symptoms and given also their stability across childhood and early adolescence they deserve to receive attention beyond the context of being precursors to other disruptive behavior disorders. A clinical implication of the findings is that ODD and CD do not represent the same underlying pathology and possibly require different treatment.

Acknowledgments Support for the first author was provided by The Swedish Council for Working Life and Social Research.

Conflict of interest None.

Open Access This article is distributed under the terms of the Creative Commons Attribution Noncommercial License which permits any noncommercial use, distribution, and reproduction in any medium, provided the original author(s) and source are credited.

\section{References}

1. Loeber R, Burke JD, Lahey BB, Winters A, Zera M (2000) Oppositional defiant disorder and conduct disorder: a review of the past 10 years, part I. J Am Acad Child Psychiatry 39:468-1484

2. Burke JD, Loeber R, Lahey BB, Rathouz PJ (2005) Developmental transitions among affective and behavioral disorders in adolescent boys. J Child Psychol Psychiatry 46:1200-1210

3. Harvey EA, Youngwirth SD, Thakar DA, Errazuriz P (2009) Predicting attention-deficit/hyperactivity disorder and oppositional defiant disorder from preschool diagnostic assessments. J Consult Clin Psychiatry 77:349-354

4. Whittinger NS, Langley K, Fowler TA, Thomas H, Thapar A (2007) Clinical precursors of adolescent conduct disorder in children with attention-deficit/hyperactivity disorder. J Am Acad Child Psychiatry 46:179-187

5. Lahey BB, Loeber R, Burke JD, Rathouz PJ, McBurnett K (2002) Waxing and waning in concert: dynamic comorbidity of conduct disorder with other disruptive and emotional problems over 7 years among clinic-referred boys. J Abnorm Psychol 111:556-567

6. August GJ, Realmuto GM, Tamara J, Hektner JM (1999) Persistence and desistance of oppositional defiant disorder in a community sample of children with ADHD. J Am Acad Child Psychiatry 38:1262-1270

7. Biederman J, Petty CR, Dolan C, Hughes EM, Monuteaux MC, Faraone SV (2008) The long- term longitudinal course of oppositional defiant disorder and conduct disorder in ADHD boys: findings from a controlled 10-year prospective longitudinal follow-up study. Psychol Med 38:1027-1036

8. Costello EJ, Mustillo S, Erkanli A, Keeler G, Angold A (2003) Prevalence and development of psychiatric disorders in childhood and adolescence. Arch Gen Psychiatry 60:837-844

9. Lahey BB, van Hulle CA, Ratouz PJ, Lee Rodgers J, D’Onofrio BM, Waldman ID (2009) Are oppositional-defiant and hyperactive-inattentive symptoms developmental precursors to conduct problems in late childhood?: genetic and environmental links. J Abnorm Child Psychiatry 37:45-58

10. Mannuzza S, Klein RG, Abikoff H, Moulton JL (2004) Significance of childhood conduct problems to later development of conduct disorder among children with ADHD: a prospective follow up study. J Abnorm Child Psychiatry 32:565-573

11. Rowe R, Maughan B, Pickles A, Costello E, Angold A (2002) The relationship between DSM-IV oppositional defiant disorder and conduct disorder: findings from the Great Smoky Mountains Study. J Child Psychol Psychiatry 43:365-373

12. Speltz ML, McClellan J, DeKlyen M, Jones K (1999) Preschool boys with oppositional defiant disorder: clinical presentation and diagnostic change. J Am Acad Child Psychiatry 38:838-845

13. Goodman SH, Lahey BB, Fielding B, Dulcan M, Regier D (1997) Representativeness of clinical samples of youths with mental disorders: a preliminary population-based study. J Abnorm Psychol 106:3-14

14. American Psychiatric Association (1994) Diagnostic and statistical manual of mental disorders, 4th edn. American Psychiatric Association, Washington, DC

15. Rutter M, Kim-Cohen J, Maughan B (2006) Continuities and discontinuities in psychopathology between childhood and adult life. J Child Psychol Psychiatry 47:276-297

16. Maughan B, Rowe R, Messer J, Goodman R, Meltzer H (2004) Conduct disorder and oppositional defiant disorder in a national sample: developmental epidemiology. J Child Psychol Psychiatry 45:609-621

17. Moffitt T, Caspi A, Rutter M, Silva PA (2001) Sex differences in antisocial behaviour: conduct disorder, delinquency, and violence in the Dunedin longitudinal study. Cambridge University Press, Cambridge

18. Waschbush DA (2002) A meta-analytic examination of comorbid hyperactive-impulsive-attention problems and conduct problems. Psychol Bull 28:118-150

19. Verhulst FC, Akkerhuis GW, Althaus M (1985) Mental health in Dutch children (I) A cross-cultural comparison. Acta Psychiatr Scand 323:1-108

20. Achenbach TM (1991) Manual for the child behavior checklist/ 4-18 and 1991 profile. University of Vermont, Department of Psychiatry, Burlington, VT

21. Achenbach TM, Edelbrock CS (1983) Manual for the child behavior checklist and revised child profile. University of Vermont, Department of Psychiatry, Burlington, VT

22. Verhulst FC, van der Ende J, Koot JM (1996) Handleiding voor de CBCL/4-18 (Manual for the CBCL/4-18). Rotterdam: Afdeling Kinder- en Jeugdpsychiatrie, Sophia Kinderziekenhuis/Akamedish Ziekenhuis Rotterdam/Erasmus Universiteit Rotterdam

23. Achenbach TM, Rescorla LA (2001) Manual for the ASEBA school-age forms \& profiles. University of Vermont, Research Center for Children, Youth, \& Families, Burlington, VT

24. Krol NPCM, De Bruyn EEJ, Coolen JC, van Aarle EJM (2006) From CBCL to DSM: a comparison of two methods to screen for DSM-IV diagnoses using CBCL data. J Clin Child Adol Psychol 35:127-135

25. Nakamura BJ, Ebesutani C, Bernstein A, Chorpita BF (2009) A psychometric analysis of the child behavior checklist DSMoriented scales. J Psychopathol Behav 31:178-189 
26. Muthén LK, Muthén BO (1998-2006) Mplus user's guide, 5th edn. Muthén \& Muthén, Los Angeles, CA

27. Brown M, Cudeck R (1993) Alternative ways of assessing model fit. In: Bollen K, Long J (eds) Testing structural equation models. Sage, London, pp 136-162

28. McCallum RC, Browne MW, Cai L (2006) Testing differences between nested covariance structure models: power analysis and null hypotheses. Psychol Methods 11:19-39

29. van Westerlaak JH, Kropman JA, Collaris JWM (1975) Beroepenklapper (Manual for occupational level). Instituut voor Sociologie, Nijmegen

30. Collins LM, Schafer JL, Kam CM (2001) A comparison of inclusive and restrictive strategies in modern missing data procedures. Psychol Methods 6:330-351
31. Satorra A, Bentler PM (2001) A scaled difference chi-square test statistic for moment structure analysis. Psychometrika 66:507-514

32. Hu L, Bentler PM (2005) Cutoff criteria for fit indexes in covariance structure analysis: conventional criteria versus new alternatives. Struct Equ Modeling 6:1-55

33. Eccles JS (2005) Studying the development of learning and task motivation. Eur Res Int 15:161-171

34. Ebesutani C, Bernstein A, Nakmura BJ, Chorpita BF, HigaMcMillan CK, Weisz JR (2010) Concurrent validity of the child behavior checklist dsm-oriented scales: correspondence with DSM diagnoses and comparison to syndrome scales. J Psychopath Behav Assess 32:373-384 